\title{
Fast Fabrication of 1.26-Meter-Long Optic for Elliptic Cylindrical Focusing Bending Mirror
}

\author{
Jieli Wu ${ }^{1, *}$, Haitao Liu ${ }^{1}$, Fengtao Yan ${ }^{1}$, Min Zhou ${ }^{1}$, Bing Zhuo ${ }^{1}$, Wan Yongjian ${ }^{1}$ \\ ${ }^{1}$ Institute of Optics and Electronics, Chinese Academy of Sciences, NO.1 Guangdian Avenue Chengdu, China
}

\begin{abstract}
As beamline emittance reaching the diffraction limit, the demand for focusing mirrors over one meter in length is ever increasing. Bending mirrors, are competitive for its adjustable radius and high manufacture precision, whose final surface form is managed by a delicate bending of a high precision plane. A special contour plays an essential role and benefits this final touch, given that the computed torque along the length closely correlates with the corresponding width of the optics. However, it poses main challenges with severe edge effect, deformation and metrology to the fabrication of the precursor plane mirror. This paper reports on a fast processing technology for a 1.26-meter-long plane as a bending mirror with irregular shape. A smooth surface with a slope error of $0.67 \mathrm{urad}(\mathrm{RMS})$ and $0.3 \mathrm{~nm}$ roughness is achieved through deterministic flexible finishing of robot polishing system and annular polishing, providing a high precision and cost-effective method to meet the growing needs for long X-ray mirrors.
\end{abstract}

\section{Introduction}

Highly brilliant and coherent X-ray beams are provided by undulators at the third-generation synchrotron radiation sources such as Advanced Photon Source (APS), European Synchrotron Facility (ESRF), SPring-8 and Shanghai Synchrotron Radiation Facility (SSFR) [1, 2]. As the development of synchrotron radiation sources, the demand for focusing mirror over one meter in length is greater than ever, which brings bigger challenge to figuring.

Bending mirror, with the advantage of adjustable radius and relative high manufacture precision, is more applicable for elliptic cylindrical mirrors of this length. Yet, in order to bend the plane mirror into ideal surface form, the contour is designed into special shaped according to the computed torque. Edge effect, deformation and sub-aperture stitching measure error inevitably hinders the surface precision optimization for the lengthy and special- shaped optics.

In this research, deterministic flexible finishing of robot polishing system and annular polishing were utilized in sequence which realized a high figuring efficiency and smooth surface for the 1.26-meter-long heteroideus plane.

\section{Fabrication system and surface figuring method}

\subsection{26-Meter-long heteroideus plane}

The parameter of the 1.26-meter-long heteroideus plane is listed in the Table 1. The shape is composed of segmental straight lines along the longitude direction which were symmetrical in width direction as shown in figure 1 .

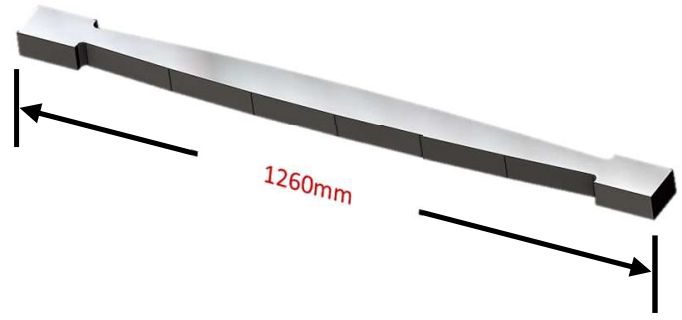

Fig. 1. 1.26-meter-long heteroideus plane

Table 1. Formatting sections, subsections and subsubsections.

\begin{tabular}{|c|c|}
\hline $\begin{array}{c}\text { Substrate } \\
\text { material }\end{array}$ & $(110)$ Si single crystal \\
\hline Mirror size & $1260 \mathrm{~mm} * 80 \mathrm{~mm} * 50$ \\
\hline $\begin{array}{c}\text { Effective } \\
\text { mirror size in } \\
\text { longitude } \\
\text { direction }\end{array}$ & $1000 \mathrm{~mm}$ \\
\hline $\begin{array}{c}\text { Acceptance } \\
\text { width }\end{array}$ & $20 \mathrm{~mm}$ \\
\hline
\end{tabular}

The figuring of the optic includes finishing of robot system and smoothing of annular lapping which processed sequentially.

\subsection{Deterministic flexible finishing of robot polishing system}

* Corresponding author: author@e-mail.org 
Like the conventional polishing, material removal of robot polishing system is based on the Preston equation, yet the flexible 6-axis moving arm and the 2-meter arm reach of robot polishing system make it a cost-effective finishing method for large unconventional optics. The typical procedure for the heteroideus plate are shown in figure 2 , in which the edge effect suppression is added. The edge warp was successfully restrained below $2 \mathrm{um}$ and smoothly connected to the near area.

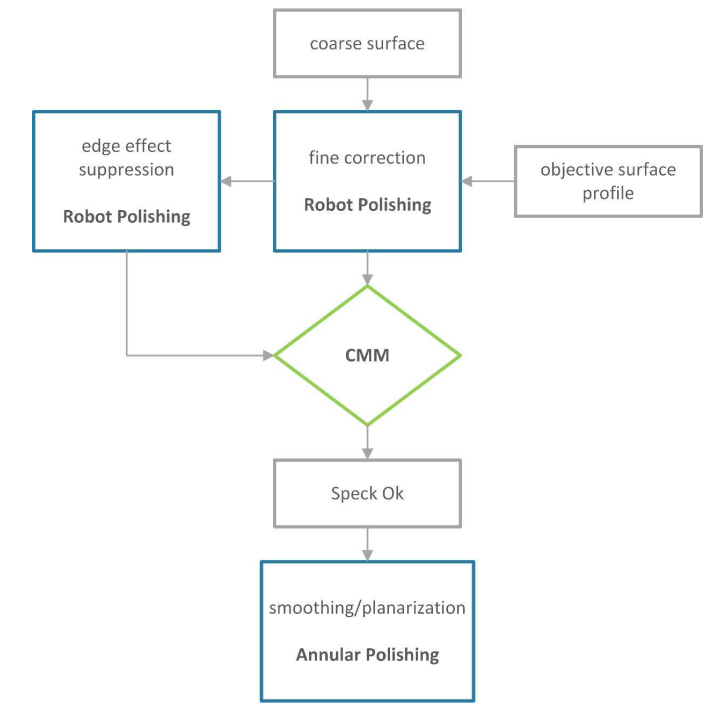

Fig. 2. Robot polishing process

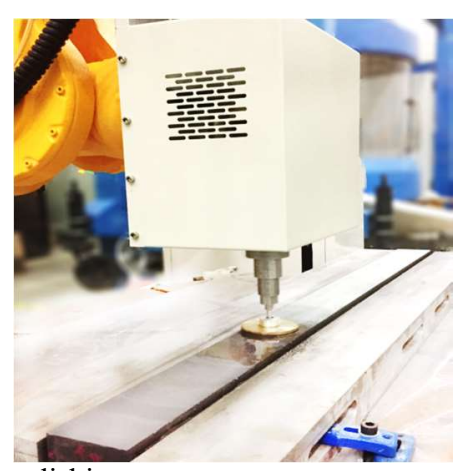

Fig. 3. Robot polishing

\subsection{Annular Polishing}

Further figuring was performed on a $5 \mathrm{~m}$ annular polishing machine shown in figure 3 . With the optimized pitch grid size, fine abrasive, slurry concentration and velocity, the plane was further planarized and smoothed.

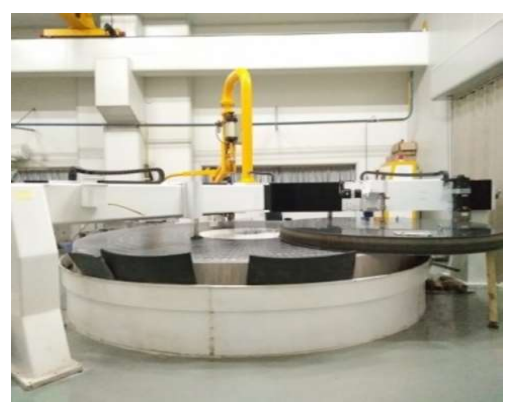

Fig. 4. 5-meter annular polishing machine

Since the polishing lap of annular polishing is much larger than the optic, it offers a global surface planarization requiring no stitching measurement during the process. The plane was then fast figured and smoothed.

\section{Results and discussion}

The fabricated surface accuracy was measured by Zygo Verifire 6" interferometer along the longitude direction, with 11 measuring spots to cover the full-aperture surface. The slope errors of the 11 spots have preferable consistency around 0.67 urad due to the planarization of annular polishing (fig.5 and fig.6). The surface roughness was measured to be $0.297 \mathrm{~nm}$ (RMS) by NanoCam Sq Dynamic Optical Profiler (fig.7).

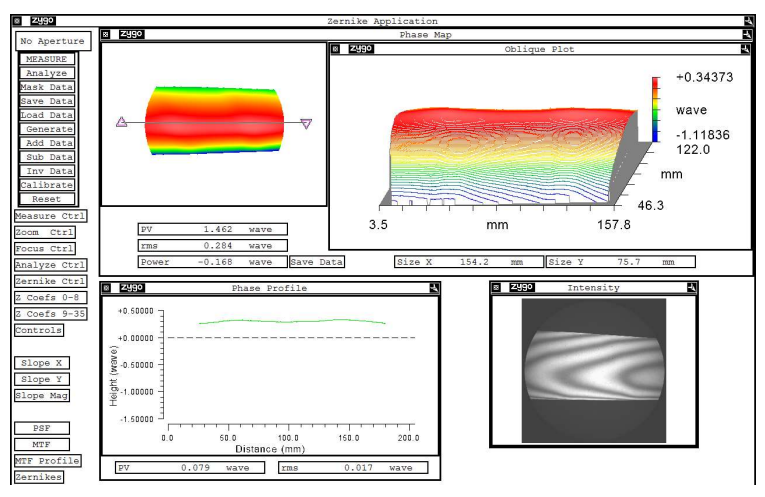

Fig. 5. Typical surface form accuracy of the fabricated mirror

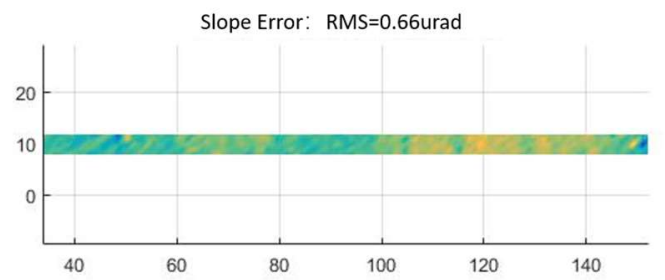

Fig. 6. Typical surface form accuracy of the fabricated mirror

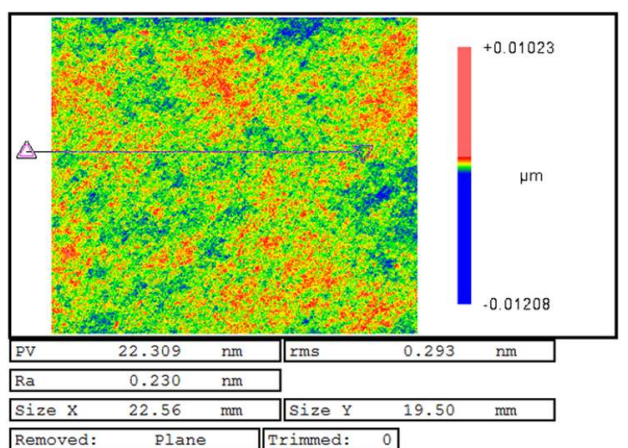

Fig. 7. Typical surface roughness of the fabricated mirror

\section{References}

1. S. Mobilio, F. Boscherini, C. Meneghini, synchrotron radiation: Basics, methods and applications (Springer-Verlag Berlin Heidelberg, 2015)

2. K. Yamauchi, K. Yamamura; H. Mimura, Y. Sano,; S. Matsuyama, H. Yumoto, K. Ueno, M. Shibahara, K. Endo, M. Yabashi, K. Tamasaku, Y. Nishino, T. Ishikawa, Y. Mori, Proc SPIE, 5533 :116 (2004) 